\title{
Giant Ovarian Cyst Presenting as an Intra-Abdominal Mass
}

\author{
Dhruv Narayan¹, Archit Jain², Amit Shrivastava ${ }^{3}$, Gunjan Jindal ${ }^{4}$, Komal Yadav ${ }^{5}$ \\ 1, 2, 3, 4, 5 Department of Radiodiagnosis, Maharishi Markandeshwar Institute of Medical Sciences and Research, \\ MMDU, Ambala, Haryana, India.
}

\section{INTRODUCTION}

Giant ovarian cysts are tumours of the ovary presenting with diameters greater than $10 \mathrm{~cm}$. They have become rare in recent days as they are diagnosed and managed early due to the modern imaging modalities. An 18-year-old female patient was admitted with abdominal distension and was detected to have a serous cystadenoma measuring $33 \mathrm{~cm}$ arising from the right ovary, which is presented in this report. Our aim is to show how a huge cystic ovarian mass can mislead the diagnosis of ascites or mesenteric/omental cysts in an adolescent woman.

Cystic abdominopelvic tumours are common and are diagnosed early due to the availability of modern imaging modalities. The differential diagnosis is extensive and includes paraovarian cyst, peritoneal/mesenteric cyst, appendiceal mucocele, cystic adenomyosis etc. ${ }^{1}$ Ovarian cysts rarely reach a large size and are generally asymptomatic at early stages and causing symptoms only after reaching enormous dimensions. The symptoms include progressive abdominal distension, nonspecific abdominal pain, constipation, early satiety, vomiting and frequent micturition. Only a few cases of giant ovarian cysts have been sporadically reported in the literature. ${ }^{2,3,4}$ Serous tumours are the most common cystic neoplasms of the ovary, $60 \%$ of which are benign. Surgical management is the preferred treatment. We present a case of a giant ovarian cyst (GOC) in an 18-year-old female that turned out to be a benign serous cystadenoma of the ovary on histopathological examination. Very few cases of GOCs masquerading as ascites or mesenteric cysts have been reported. ${ }^{5}$ This case is reported to increase the suspicion index of serous cystadenoma in the case of giant intra-abdominal cysts in young women.

\section{PRESENTATION OF CASE}

An 18 year old female presented with a history of progressive abdominal distension for the last 9-10 months. She had no abdominal pain, nausea, vomiting or bowel/bladder abnormalities. She had significant abdominal distension with visible striae marks and full flanks. It was soft and non-tender. Percussion notes revealed dullness over the entire abdomen with a fluid thrill. No tenderness or guarding was present. Examination of the urogenital system was unremarkable. Blood tests were normal with no relevant past medical history. An ultrasound scan was performed which revealed a massive, well defined, thin-walled abdominopelvic cystic lesion [Figure 1A]. It showed few internal echoes and was extending from the epigastrium to the pelvis. No internal septations, solid components or internal vascularity were seen. The bowel loops were displaced peripherally. Based on the ultrasound appearance, our first differential diagnosis was a large ovarian cyst with mesenteric/omental cyst being the second possibility. Non-contrast CT findings corroborated with USG and showed a large unilocular cystic lesion with fluid attenuation with no solid nodules, septations or calcifications [Figure 1B-D].

\author{
Corresponding Author: \\ Dr. Archit Jain, \\ Department of Radiodiagnosis, \\ Maharishi Markandeshwar Institute of \\ Medical Sciences and Research, \\ MMDU, Mullana, 133207, \\ Ambala, Haryana, India. \\ E-mail:architjain0612@gmail.com
}

DOI: $10.14260 / j e m d s / 2022 / 83$

How to Cite This Article:

Narayan D, Jain A, Shrivastava A, et al. Giant ovarian cyst presenting as an intraabdominal mass. J Evolution Med Dent Sci 2022;11(03):428-430, DOI: $10.14260 / \mathrm{jemds} / 2022 / 83$

Submission 09-01-2022,

Peer Review 04-02-2022,

Acceptance 11-02-2022,

Published 25-02-2022.

Copyright (C) 2022 Dhruv Narayan et al. This is an open access article distributed under Creative Commons Attribution License [Attribution 4.0 International (CC BY 4.0)] 

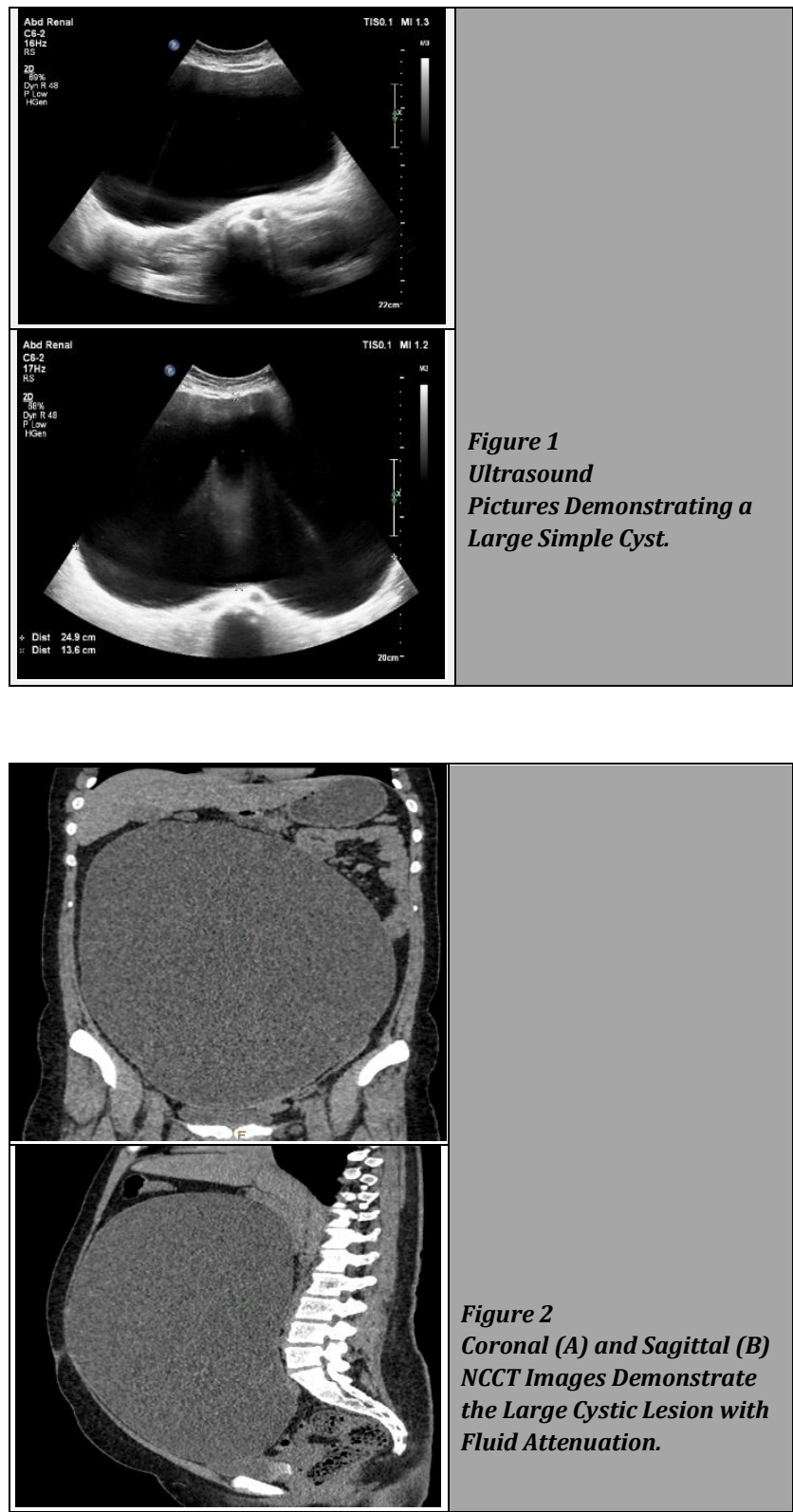

To confirm ultrasound findings and for preoperative assessment, contrast-enhanced MRI was done which showed a large thin-walled unilocular cystic lesion in the abdomen and pelvis measuring $33 \mathrm{~cm}$ (CC) x $26 \mathrm{~cm}$ (TR) x $16 \mathrm{~cm}$ (AP). It appeared hypointense on $\mathrm{T} 1 \mathrm{~W}$ images and hyperintense on $\mathrm{T} 2 \mathrm{~W}$ images. The lesion was abutting the right ovary with a mass effect noted over the bowel loop [Figure 2].

No septations, solid component, abnormal contrast enhancement or diffusion restriction was seen. In view of large size, we kept mucinous cystadenoma as the first diagnosis. Based on the unilocular nature, we kept serous cystadenoma as the second possibility. Tumour markers CA125, serum CEA and Beta HCG levels were normal. Laparoscopic ovarian cystectomy with neosalpingostomy was performed. Intraoperatively, a huge ovarian cyst was present from the pouch of Douglas till the diaphragm arising from the right ovary. No evidence of excrescences or capsule breach was seen. Approximately 8 litres of clear fluid was drained from the cyst. There was no ascites, peritoneal implants or liver nodules. The left ovary, fallopian tubes, uterus and appendix were normal. She had an unremarkable postoperative period and was discharged on the 5th post- operative day. The pathology report revealed an ovarian serous cystadenoma [Figure 3]. The cyst had a thin wall, partly composed of ovarian stroma and partly by fibro collagenous tissue. No evidence of stratification, atypia or malignancy was noted.
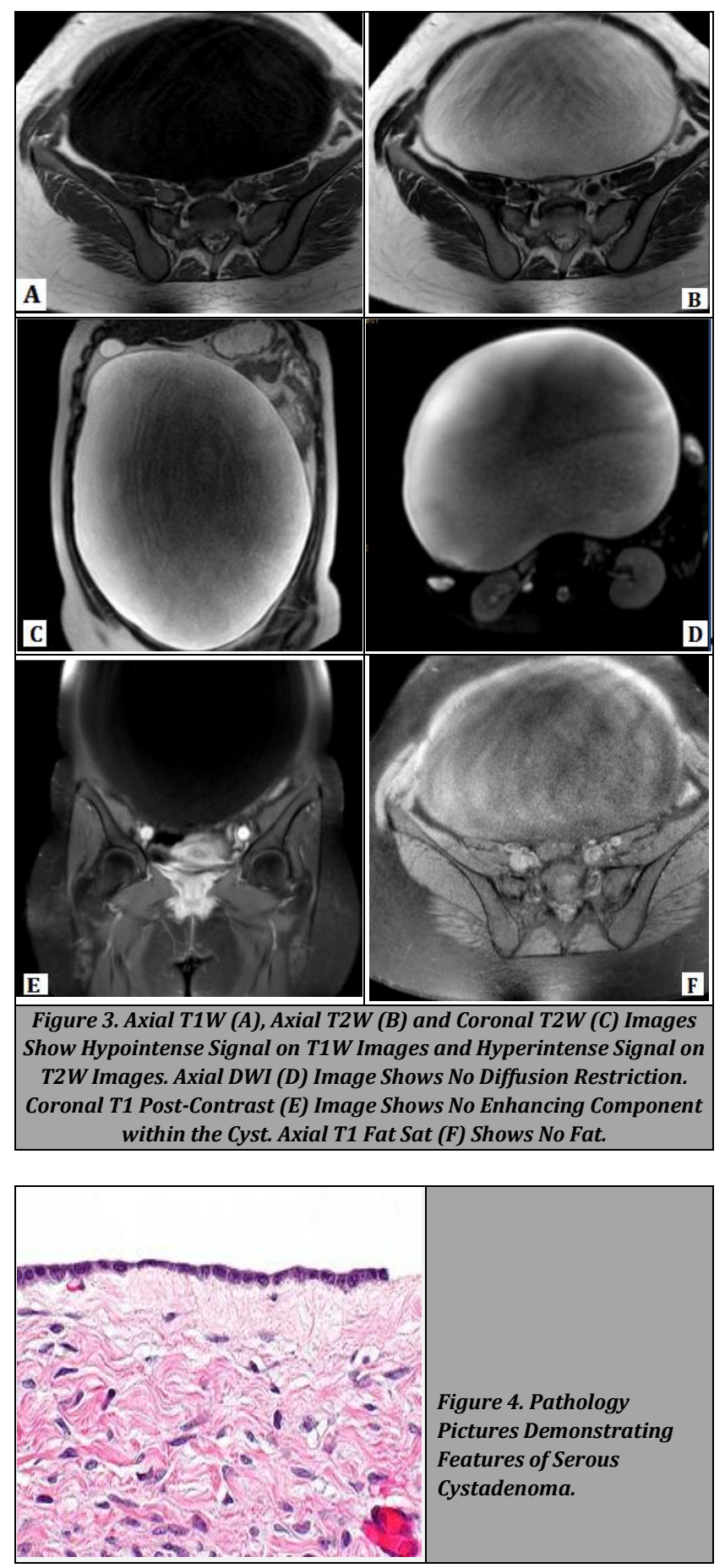

\section{DISCUSSION}

GOCs have become rare in current medical practice due to the widespread use of modern imaging techniques. Detection of ovarian cyst causes considerable worry for women because of fear of malignancy. Many ovarian tumours present as cysts, but all cysts are not tumours. Serous tumours are the most common cystic neoplasms of the ovary, $60 \%$ of which are 
benign. 6 The definition of GOCs has not been well described in the literature. Some authors define GOCs as those more than $10 \mathrm{~cm}$ in diameter measured on the preoperative scan. ${ }^{7}$ Others define GOCs as those reaching above the umbilicus. ${ }^{8,9}$ The case under-report well fits into the criteria of GOC. Benign serous cystadenoma is reported to occur in middleaged women. Studies in the literature substantiate the rarity of giant ovarian cysts in adolescent females. Ours was an adolescent female and serous cystadenomas are uncommon at such an age. In our case, the tumour was a unilateral, thinwalled cyst of the right ovary filled with clear fluid. One of the major differential diagnoses of ovarian cysts is mesenteric cysts. Mesenteric cysts can occur in all age groups, but most often they present in children and young adults. These masses may be simple or multiple and may be huge. Therefore, ascites is another entity that must be included in the list of differential diagnoses. Surgical management of cysts is by laparotomy or laparoscopic cyst excision or cystectomy with oophorectomy. Although many studies have advocated and claimed successful removal of giant/large/huge ovarian cysts laparoscopically yet there is hardly any study that has claimed laparoscopic removal of large ovarian cysts. ${ }^{10}$ Our study is an exception to this as the cyst was successfully operated laparoscopically without any complications.

\section{CONCLUSIONS}

GOCs are rarely encountered in modern medicine. Progressive abdominal distension in premenopausal women should be considered a red flag of ovarian tumour. Large cystic ovarian tumours can masquerade as mesenteric/ omental cysts thereby misleading the diagnosis. We report this case to increase the suspicion index of a large ovarian cyst in women presenting with distended abdomen which can be diagnosed by ultrasound and characterised on MRI. Our case is also one of the rare cases reported as giant serous cystadenoma at a younger age.

\section{REFERENCES}

[1] Zanini P, Cavalca A, Benatti E, et al. Benign giant ovarian cystadenoma. Description of a clinical case. Minerva Ginecol 1996;48(5):215-9.

[2] Farinetti A, Butazzi A, Tazzioli G, et al. Giant ovarian cyst. A case weighing $23 \mathrm{~kg}$ and literature review. Minerva Chir 2003;58(2):261-5.

[3] Hunter DJ. Management of massive ovarian cyst. Obstet Gynecol 1980;56(2):254-5.

[4] Ishioka S, Sagae S, Ito E, et al. Ultrastructural study of benign, low-malignant potential (LMP), and malignant ovarian tumors. Med Electron Microsc 2004;37(1):3744.

[5] Ou CS, Liu YH, Zabriskie V, et al. Alternate methods for laparoscopic management of adnexal masses greater than $10 \mathrm{~cm}$ in diameter. J Laparoendosc Adv Surg Tech A 2001;11(3):125-32.

[6] Salem HA. Laparoscopic excision of large ovarian cysts. J Obstet Gynaecol Res 2002;28(6):290-4.

[7] Bhasin SK, Kumar V, Kumar R. Giant ovarian cyst: a case report. JK Science 2014;16(3):131-3.

[8] Zamora-Garza M, Rizo J, Dominquez A. Giant ovarian cyst: case report. Am J Obstet Gynecol 1992;166(4):1247-8.

[9] Leite C, Barbosa B, Santos N, et al. Giant abdominal cyst in a young female patient: a case report. Int J Surg Case Rep 2020;72:549-55.

[10] Yeika EV, Efie DT, Tolefac PN, et al. Giant ovarian cyst masquerading as a massive ascites: a case report. BMC Res Notes 2017;10(1):749. 